\title{
Analysis of the Mechanism of Inhibition of Human Matrix Metalloproteinase 7 (MMP-7) Activity by Green Tea Catechins
}

\author{
Tomoko Miyake, Kiyoshi Yasukawa, and Kuniyo Inouye ${ }^{\dagger}$ \\ Division of Food Science and Biotechnology, Graduate School of Agriculture, Kyoto University, \\ Sakyo-ku, Kyoto 606-8502, Japan
}

Received April 1, 2011; Accepted May 9, 2011; Online Publication, August 7, 2011

[doi:10.1271/bbb.110257]

Green tea catechins inhibit human matrix metalloproteinase 7 (MMP-7) activity non-competitively, and the galloyl group is essential for potent inhibition (Oneda et al., J. Biochem., 133, 571-576 (2003)). In this study, we analyzed the mechanism of this inhibition. In the hydrolysis of (7-methoxycoumarin-4-yl)acetyl-L-Pro-LLeu-Gly-L-Leu-[ $N^{3}$-(2,4-dinitrophenyl)-L-2,3-diaminopropionyl]-L-Ala-L-Arg- $\mathrm{NH}_{2}$, the inhibitory effects of (-)-epigallocatechin-3-gallate (EGCG), (-)-gallocatechin-3-gallate (GCG), (-)-epicatechin-3-gallate (ECG), and (-)-catechin-3-gallate (CG) increased with increasing $\mathrm{pH}$ levels from 7.0 to 8.5. The inhibitory effects of EGCG and GCG were more potent than those of ECG and $\mathrm{CG}$, and increased with increasing $\mathrm{CaCl}_{2}$ concentrations from 10 to $50 \mathrm{~mm}$. The fluorescence of EGCG and GCG decreased with increasing $\mathrm{CaCl}_{2}$ concentrations and with the addition of MMP-7, while those of ECG and CG did not. Our results suggest that these differences result from that in the B ring, EGCG and GCG have phenol hydroxyl groups at the $3^{\prime}, 4^{\prime}$, and $5^{\prime}$ positions, while ECG and CG have them at the $3^{\prime}$ and $4^{\prime}$ positions.

Key words: calcium; fluorescence; green tea catechins; matrix metalloproteinase; matrix metalloproteinase (MMP)-7

Human matrix metalloproteinase 7 (MMP-7, Matrilysin) [EC 3.4.24.23] is the smallest matrix metalloproteinase (MMP). It lacks a carboxyl terminal hemopexin-like domain, which is conserved in most MMPs. It is believed to play important roles in tumor invasion and metastasis. ${ }^{1,2)}$ The molecular mass of the latent pro-form is $28 \mathrm{kDa}$, and that of the mature form is $19 \mathrm{kDa} .{ }^{3)}$ MMP-7 is composed of a five-stranded $\beta$-sheet and three $\alpha$-helices, and contains a zinc ion, essential for activity, and other zinc and two calcium ions that are considered necessary for stability. ${ }^{4}$ Like all other MMPs, it has consensus sequence HEXXHXXGXXH, in which three histidine residues chelate a catalytic zinc ion, and a methionine-containing turn (Met-turn). Hence it is grouped in clan MA(M) ${ }^{5)}$ In recent years, target molecules through which MMP-7 exerts biological functions have become apparent, including heparin, ${ }^{6)}$ heparan sulfate, ${ }^{7)}$ cholesterol sulfate, ${ }^{7,8)}$ and ErbB4 receptor. ${ }^{9)}$

MMP-7 has been detected in lesions of the prostate, ${ }^{10}$ ) colon, ${ }^{11)}$ brain, ${ }^{12)}$ stomach, ${ }^{13)}$ lung, ${ }^{14)}$ and breast, ${ }^{15)}$ and degrades extracellular material components, including gelatins of types I, III, IV, and V, type IV basement membrane collagen, fibronectin, vitronectin, proteoglycan, laminin, and elastin, ${ }^{3,16-18)}$ suggesting that it plays a role in tumor invasion and metastasis. Hence the development of MMP-7 inhibitors is considered to be of therapeutic benefit. We have reported states of the tryptophyl residues of MMP-7 as determined by fluorescence examination ${ }^{19)}$ and its thermal stability and halophilic properties. ${ }^{20)}$ We have also reported the inhibitory effects of alcohols, ${ }^{21)}$ synthetic MMP inhibitors thiorphan and R-94138, ${ }^{22)}$ lignans, ${ }^{23)}$ and green tea catechins $^{24)}$ on MMP-7 activity.

Catechins are flavonoids, and are currently an attractive research subject because of their abundance in human diet and various biological functions with possible beneficial health effects. Green tea contains catechins abundantly, and thus a high intake of green tea is thought to be effective for the prevention of tumors. In green tea, (-)-epigallocatechin-3-gallate (EGCG) is the most abundant (40-60\%), followed by (-)-epicatechin3-gallate (ECG, 10-20\%), (-)-epigallocatechin (EGC, $10-20 \%$ ), and (-)-epicatechin (EC, 4-6\%). ${ }^{25)}$ Recently, various physiological activities of green tea catechins have been noted, including hepatotoxic, anti-nutritional, carcinogenic, anti-mutagenic, anti-microbial, anti-viral, and immunomodulating activities, ${ }^{26)}$ but the molecular mechanisms of their biological functions are in most cases unclear. Recently, certain enzymes have been identified as possible targets of catechins, including MMPs. ${ }^{24,27-30)}$

We have reported that green tea catechins inhibit human MMP-7 activity non-competitively, and that the galloyl group is essential for potent inhibition. ${ }^{24)}$ In this study, to explore the mechanism of inhibition, we examined the effects of $\mathrm{pH}$ and $\mathrm{Ca}^{2+}$ on the inhibition of MMP-7 activity by catechins and the effects of $\mathrm{Ca}^{2+}$, MMP-7, and ethanol on the fluorescence of catechins. We also discuss the mechanism of the inhibition of MMP-7 activity by catechins. 


\section{Materials and Methods}

Materials. A substrate of MMP-7, (7-methoxycoumarin-4-yl)acetylL-Pro-L-Leu-Gly-L-Leu-[ $N^{3}$-(2,4-dinitrophenyl)-L-2,3-diaminopropionyl]-

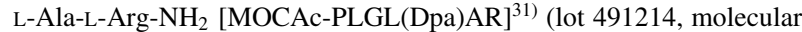
mass 1,093.2 Da), and (7-methoxycoumarin-4-yl)acetyl-L-Pro-L-LeuGly (MOCAc-PLG) (lot 510913, molecular mass 501.53 Da) were purchased from the Peptide Institute (Osaka, Japan). Their concentrations were determined by the denoted weight and the molecule weight. (-)-Epigallocatechin-3-gallate (EGCG) (lot V8K7794 molecular mass 458.37 Da), (-)-gallocatechin-3-gallate (GCG) (lot V8F7006, 458.37 Da), (-)-epi-catechin-3-gallate (ECG) (lot V8H7625, 442.37 Da), (-)-catechin-3-gallate (CG) (lot Z8P9183, 442.37 Da), and (-)-epigallocatechin (EGC) (lot V8G7379, 306.27 Da) were from Nacalai Tesque (Kyoto, Japan). Figure 1 shows their molecular structures. Butylhydroxytoluene (BHT) was from Wako Pure Chemical (Osaka, Japan). All other chemicals were from Nacalai Tesque.

Expression and purification of MMP-7. Expression in Escherichia coli and purification of recombinant MMP-7 were carried out as described previously. ${ }^{32-36)}$ The concentration of MMP-7 was determined spectrophotometrically using a molar absorption coefficient at $280 \mathrm{~nm}, \varepsilon_{280}$, of $31,800 \mathrm{M}^{-1} \mathrm{~cm}^{-1}$. $^{33)}$

MMP-7-catalyzed hydrolysis of MOCAc-PLGL(Dpa)AR. Catechins were dissolved in ethanol plus $0.1 \% \mathrm{w} / \mathrm{v}$ BHT. Pre-incubation was initiated by mixing $15 \mu \mathrm{L}$ of MMP-7 solution $(1.8 \mu \mathrm{M}), 21.7 \mu \mathrm{L}$ of catechin solution $(0-10 \mathrm{~mm})$, and $2,663.3 \mu \mathrm{L}$ of $50 \mathrm{mM}$ HEPES-NaOH buffer ( $\mathrm{pH} 7.0-8.5$ ) containing various concentrations of $\mathrm{CaCl}_{2}, \mathrm{NaCl}$, and/or $\mathrm{KCl}$ at $25^{\circ} \mathrm{C}$ for $30 \mathrm{~min}$. After pre-incubation, the reaction was initiated by adding $16 \mu \mathrm{L}$ of the substrate solution $(234 \mu \mathrm{M})$ dissolved in DMSO. The reaction was measured by following the increase in fluorescence intensity at $393 \mathrm{~nm}, \Delta F_{393}$, with excitation at $328 \mathrm{~nm}$ with a Shimadzu RF-5300PC fluorescence spectrophotometer (Shimadzu, Kyoto, Japan) for $1 \mathrm{~min}$ at $25^{\circ} \mathrm{C}$. The temperature was maintained in a range of $\pm 0.2^{\circ} \mathrm{C}$. The peptide bond of the Gly-L-Leu residues was cleaved by MMP-7. ${ }^{20,32}$ ) The amount of the product, MOCAc-PLG, was estimated by fluorescence intensity by comparison with that of the MOCAc-PLG solution.

The $\Delta F I_{393}$ of the reaction mixture is affected by catechins. Hence $\mathrm{FI}_{393}$ was measured with various concentrations of catechins in the absence and the presence of $0.44 \mu \mathrm{M}$ MOCAc-PLG. Based on the results, the $\Delta F I_{393}$ observed at $\mathrm{x} \mu \mathrm{M}$ catechin was corrected by multiplying the following terms:

[(FI $I_{393}$ of $0.44 \mu \mathrm{M}$ MOCAc-PLG $)-\left(F I_{393}\right.$ of buffer $\left.)\right]$

$\overline{\left[\left(F_{393} \text { of } 0.44 \mu \mathrm{M} \text { MOCAc-PLG plus } \mathrm{x} \mu \mathrm{M} \text { catechin }\right)-\left(\mathrm{FI}_{393} \text { of } \mathrm{x} \mu \mathrm{M} \text { catechin }\right)\right]}$

Hydrolysis was carried out under pseudo first-order conditions, where the initial concentration of MOCAc-PLGL(Dpa)AR $(1.5 \mu \mathrm{M})$ was set much lower than the Michaelis constant, $K_{\mathrm{m}},(32 \mu \mathrm{M}),{ }^{21)}$ to avoid absorptive quenching effects. The Michaelis-Menten equation was expressed as $v=\left(k_{\text {cat }} / K_{\mathrm{m}}\right)[\mathrm{E}]_{\mathrm{o}}[\mathrm{S}]_{\mathrm{o}}$, where $v, k_{\text {cat }},[\mathrm{E}]_{\mathrm{o}}$, and $[\mathrm{S}]_{\mathrm{o}}$ are the initial reaction rate, the molecular activity, the initial enzyme concentration, and the initial substrate concentration respectively. Using this equation, enzyme activity was evaluated by the specificity constant, $k_{\text {cat }} / K_{\mathrm{m}}$.

Fluorometric analysis of green tea catechins. Catechins were dissolved in ethanol plus $0.1 \%$ BHT. Pre-incubation was initiated by mixing $21.7 \mu \mathrm{L}$ of the catechin solution $(1 \mathrm{mM})$ and $2,678.3 \mu \mathrm{L}$ of $50 \mathrm{mM}$ HEPES-NaOH buffer ( $\mathrm{pH} 8.5$ ) containing various concentrations of $\mathrm{CaCl}_{2}, \mathrm{NaCl}, \mathrm{KCl}, \mathrm{MMP}-7$, and ethanol at $25^{\circ} \mathrm{C}$ for $30 \mathrm{~min}$. After pre-incubation, the fluorescence spectra were measured with excitation at $325 \mathrm{~nm}$ and emission at $350-550 \mathrm{~nm}$ with a Shimadzu RF$5300 \mathrm{PC}$ fluorescence spectrophotometer at $25^{\circ} \mathrm{C}$. pH was maintained in a range of \pm 0.1 .

Dielectric constant of the solution. The dielectric constant, D, values of the solutions containing various concentrations of ethanol were calculated by eq. $(1)^{37)}$

$$
D=78 \times f_{\mathrm{w}}+24.6 \times f_{\mathrm{e}}
$$
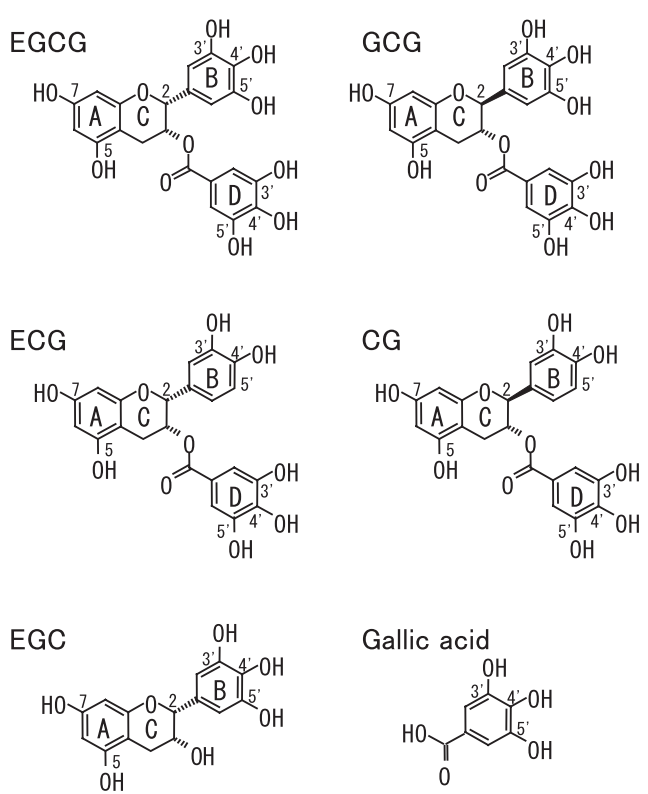

Fig. 1. Molecular Structures of Green Tea Catechins and Gallic Acid. The molecular structures of (-)-epigallocatechin-3-gallate (EGCG), (-)-gallocatechin-3-gallate (GCG), (-)-epicatechin-3-gallate (ECG), (-)-catechin-3-gallate (CG), (-)-epigallocatechin (EGC), and gallic acid are shown.

where 78 and 24.6 are the $D$ values of water and ethanol respectively, and $f_{\mathrm{w}}$ and $f_{\mathrm{e}}$ are the volume fractions of water and ethanol respectively.

\section{Results}

Effects of $p H$ on inhibition of MMP-7 activity by green tea catechins

Figure 2 shows the effects of increasing concentrations of four green tea catechins with the galloyl group (EGCG, GCG, ECG, and CG), one green tea catechin without the galloyl group (EGC), and gallic acid on MMP-7 activity hydrolyzing MOCAc-PLGL(Dpa)AR in the presence of $10 \mathrm{mM} \mathrm{CaCl}_{2}$ at $\mathrm{pH} 7.0-8.5$ at $25^{\circ} \mathrm{C}$. All the catechins and gallic acid inhibited the activity dosedependently, except for gallic acid at $\mathrm{pH}$ 7.0. The inhibitory effects increased with increasing $\mathrm{pH}$. At pH 8.5, EGCG and GCG at $40 \mu \mathrm{m}$ inhibited the activity completely (Fig. 2A and B), ECG, CG, and gallic acid at $80 \mu \mathrm{M}$ inhibited the activity by about $80 \%$ (Fig. 2C, D, and F), and EGC at $80 \mu \mathrm{M}$ inhibited the activity by about $50 \%$ (Fig. 2E). These results indicate that the inhibitory effects of catechins and gallic acid occurred in the order EGCG, GCG > ECG, CG, gallic acid > EGC. In the B ring, EGCG and GCG have phenol hydroxyl groups at the $3^{\prime}, 4^{\prime}$, and $5^{\prime}$ positions, and ECG and CG have them at the $3^{\prime}$ and $4^{\prime}$ positions (Fig. 1). Thus, the results suggest that this difference has to do with the difference in inhibitory effects on MMP-7 activity among the catechins with the galloyl group.

Effects of $\mathrm{Ca}^{2+}$ on inhibition of MMP-7 activity by green tea catechins

Figure 3 shows the effects of increasing concentrations of EGCG, GCG, ECG, and CG on the MMP-7 activity in hydrolyzing MOCAc-PLGL(Dpa)AR at $\mathrm{pH} 8.5$ at $25^{\circ} \mathrm{C}$ in the presence of $10 \mathrm{mM} \mathrm{CaCl}_{2}$, $50 \mathrm{mM} \mathrm{CaCl}_{2}, 10 \mathrm{~mm} \mathrm{CaCl}_{2}$ plus $80 \mathrm{~mm} \mathrm{NaCl}$, or $10 \mathrm{~mm}$ 
A

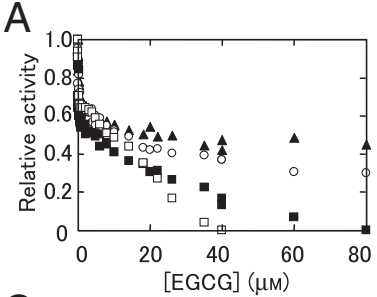

C

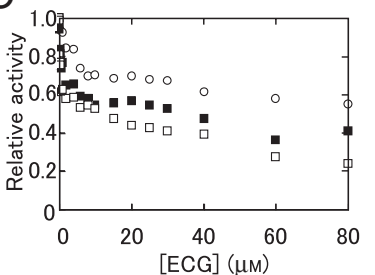

$\mathrm{E}$

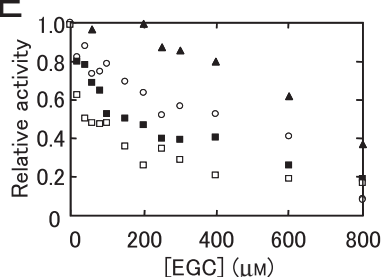

B

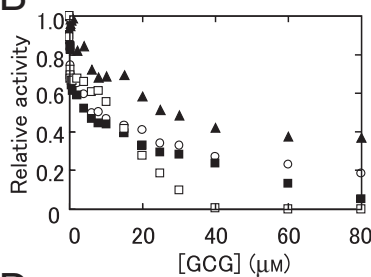

D
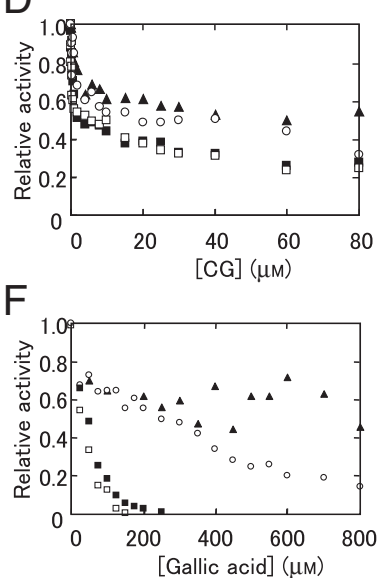

Fig. 2. Effects of $\mathrm{pH}$ on Inhibition by Green Tea Catechins of the MMP-7-Catalyzed Hydrolysis of MOCAc-PLGL(Dpa)AR.

The reaction was performed in $50 \mathrm{~mm}$ HEPES-NaOH, $10 \mathrm{~mm}$ $\mathrm{CaCl}_{2}, 0.8 \% \mathrm{v} / \mathrm{v}$ ethanol, $0.8 \times 10^{-3} \% \mathrm{w} / \mathrm{v} \mathrm{BHT}, 0.6 \% \mathrm{v} / \mathrm{v}$ DMSO, and various concentrations $(0-80 \mu \mathrm{M})$ of EGCG (A), GCG (B), ECG (C), CG (D), EGC (E), and gallic acid (F) at pH 7.0 (solid triangle), 7.5 (hollow circle), 8.0 (solid square), and 8.5 (hollow square), at $25^{\circ} \mathrm{C}$. No reaction with ECG at $\mathrm{pH} 7.0$ was performed. The initial concentrations of MMP-7 and MOCAc-PLGL(Dpa)AR were $10 \mathrm{~nm}$ and $1.5 \mu \mathrm{M}$ respectively. Relative activity indicates the initial reaction rate relative to the value obtained without catechins $\left(0.42 \mathrm{~nm} \mathrm{~s}^{-1}\right)$.

$\mathrm{CaCl}_{2}$ plus $80 \mathrm{~mm} \mathrm{KCl}$. In the presence of 10 and $50 \mathrm{~mm}$ $\mathrm{CaCl}_{2}$, EGCG and GCG completely and ECG and CG partially inhibited MMP-7 activity dose-dependently. $\mathrm{IC}_{50}$, which was defined as the catechin concentrations of EGCG and GCG required to inhibit MMP-7 activity by $50 \%$ were 5.3 and $5.8 \mu \mathrm{M}$ respectively with $50 \mathrm{~mm}$ $\mathrm{CaCl}_{2}$, lower than those with $10 \mathrm{mM} \mathrm{CaCl}_{2}$ (13.9 and $12.9 \mu \mathrm{M}$ respectively), indicating that the inhibitory effects of EGCG and GCG increased with increasing $\mathrm{CaCl}_{2}$ concentrations. No such tendency was observed for the inhibitory effects of ECG or CG. In the presence of $10 \mathrm{~mm} \mathrm{CaCl} 2$ plus $80 \mathrm{~mm} \mathrm{NaCl}$ or $80 \mathrm{~mm} \mathrm{KCl}$, the inhibitory effects of all the catechins decreased, indicating that the inhibitory effects decreased with increasing concentrations of $\mathrm{NaCl}$ or $\mathrm{KCl}$. No inhibitory effects of catechins in the presence of $\mathrm{NaCl}$ or $\mathrm{KCl}$ alone were observed, because MMP-7 requires $\mathrm{Ca}^{2+}$ for stability. These results suggest that $\mathrm{Ca}^{2+}$ but not $\mathrm{Cl}^{-}$is involved in the inhibition of MMP-7 activity by catechins. The inhibitory effects of EGCG and GCG were similar, and those of ECG and CG were also similar, suggesting that chirality at the 2 position of the $\mathrm{C}$ ring of catechins does not influence their inhibitory effects.

Effects of $\mathrm{Ca}^{2+}$ on the fluorescence of green tea catechins

To explore the interaction of catechins with $\mathrm{Ca}^{2+}$, the effects of increasing $\mathrm{CaCl}_{2}$ concentrations on the fluorescence spectra of the catechins were measured (Fig. 4). $\mathrm{pH}$ was set 8.5 , because inhibition at $\mathrm{pH} 8.5$ was the highest (Fig. 2). In the absence of $\mathrm{CaCl}_{2}$,

A

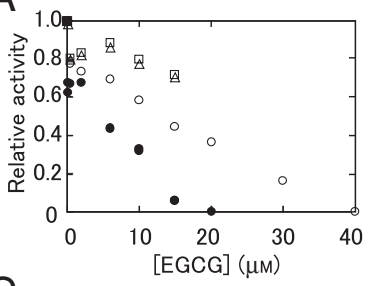

C

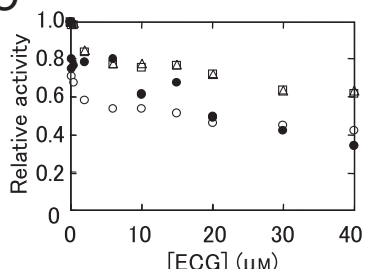

$\mathrm{B}$

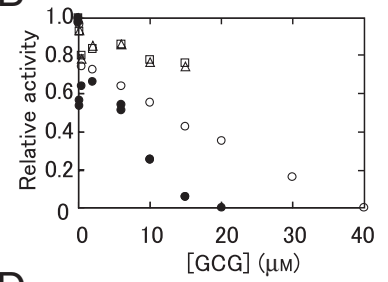

D

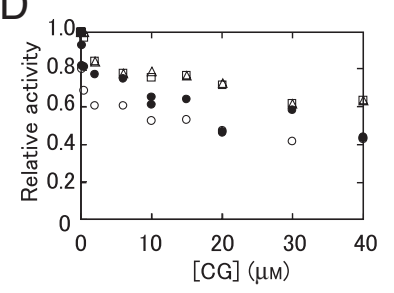

Fig. 3. Effects of $\mathrm{CaCl}_{2}$ on Inhibition by Green Tea Catechins of the MMP-7-Catalyzed Hydrolysis of MOCAc-PLGL(Dpa)AR.

The reaction was performed in $50 \mathrm{~mm}$ HEPES-NaOH, either $10 \mathrm{mM} \mathrm{CaCl}_{2}$ (hollow circle), $50 \mathrm{~mm} \mathrm{CaCl}_{2}$ (solid circle), $10 \mathrm{~mm}$ $\mathrm{CaCl}_{2}$ and $80 \mathrm{mM} \mathrm{NaCl}$ (hollow triangle), or $10 \mathrm{mM} \mathrm{CaCl}_{2}$ and $80 \mathrm{mM}$ $\mathrm{KCl}$ (hollow square), $0.8 \%$ ethanol, $0.8 \times 10^{-3} \%$ BHT, $0.6 \%$ DMSO, and various concentrations $(0-80 \mu \mathrm{M})$ of EGCG (A), GCG (B), ECG (C), and CG (D) at $\mathrm{pH} 8.5$ at $25^{\circ} \mathrm{C}$. The initial concentrations of MMP-7 and MOCAc-PLGL(Dpa)AR were $10 \mathrm{~nm}$ and $1.5 \mu \mathrm{M}$ respectively. Relative activity indicates the initial reaction rate relative to the value obtained without catechins $\left(0.35 \mathrm{nM} \mathrm{s}^{-1}\right)$.

EGCG, GCG, ECG, and CG $(8 \mu \mathrm{M})$ exhibited fluorescence spectra with similar maximum wavelengths $\left(\lambda_{\max }\right)$ of about $393 \mathrm{~nm}$. Peak fluorescence intensities were in the order ECG $>\mathrm{CG}>\mathrm{EGCG}>\mathrm{GCG}$. Increasing $\mathrm{CaCl}_{2}$ concentrations considerably decreased the fluorescence of EGCG and GCG without affecting $\lambda_{\max }$, while it slightly increased those of ECG and CG. For all catechins, fluorescence was not affected by $90 \mathrm{mM} \mathrm{NaCl}$ or $90 \mathrm{~mm} \mathrm{KCl}$ (data not shown), indicating that EGCG and GCG interact with $\mathrm{Ca}^{2+}$ but not with $\mathrm{Cl}^{-}$. Figure 4E shows relative fluorescence intensity against the $\mathrm{CaCl}_{2}$ concentration. The relative fluorescence intensities of EGCG and GCG decreased considerably with increasing $\mathrm{CaCl}_{2}$ concentrations and reached minimum $(0.16$ for EGCG and 0.13 for GCG) at $40 \mathrm{~mm}$, while those of ECG and $C G$ increased slightly with increasing $\mathrm{CaCl}_{2}$ concentrations and reached maximum (about 1.1) at $10 \mathrm{~mm}$, suggesting that EGCG and GCG interact with $\mathrm{Ca}^{2+}$ in a different fashion from ECG and CG.

Effects of MMP-7 on the fluorescence of green tea catechins

The effects of MMP-7 on the fluorescence spectra of the catechins were measured (Fig. 5). $\mathrm{pH}$ was set 8.5 and the $\mathrm{CaCl}_{2}$ concentration was set $6 \mathrm{mM}$, at which the fluorescence intensities of EGCG and GCG decreased to about $50 \%$ of those at $0 \mathrm{mM} \mathrm{CaCl}_{2}$. MMP-7 (6 $\left.\mu \mathrm{M}\right)$ enhanced the fluorescence of EGCG and GCG by 1.4 and 1.8 fold respectively, without affecting $\lambda_{\max }$, while it did not affect those of ECG or CG. This suggests that EGCG and GCG interacted with MMP-7.

Effects of ethanol on the fluorescence of green tea catechins

The effects of ethanol on the fluorescence spectra of the catechins were measured (Fig. 6). pH was set at 8.5, and the $\mathrm{CaCl}_{2}$ concentration at $6 \mathrm{~mm}$. The increasing 
A

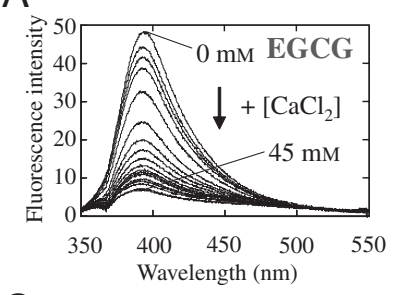

C

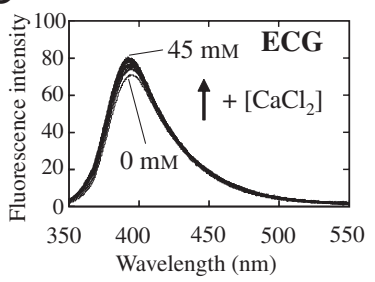

E

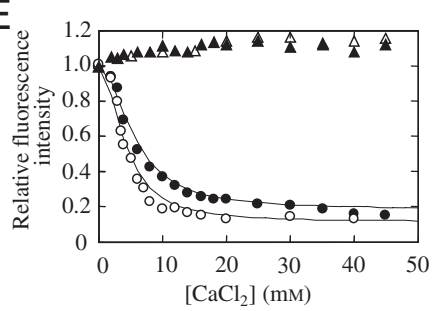

Fig. 4. Effects of $\mathrm{CaCl}_{2}$ on the Fluorescence of Green Tea Catechins. Fluorescence spectra were measured with excitation at $325 \mathrm{~nm}$ and emission at $350-550 \mathrm{~nm}$ for $8 \mu \mathrm{M}$ catechins in $50 \mathrm{~mm}$ HEPES$\mathrm{NaOH}$ containing various concentrations $(0,3,6,9,12,15,18,21$, $24,27,30,33,36,39,42$, and $45 \mathrm{~mm}$ ) of $\mathrm{CaCl}_{2}, 0.8 \%$ ethanol, and $0.8 \times 10^{-3} \%$ BHT at $\mathrm{pH} 8.5$ at $25^{\circ} \mathrm{C}$. A-D, Fluorescence spectra of EGCG (A), GCG (B), ECG (C), and CG (D). E, Relative fluorescence intensity. Relative fluorescence intensity, defined as the relative value of the area of the emission spectrum in the range of $385-400 \mathrm{~nm}$ in the presence of $\mathrm{CaCl}_{2}$ to the value in its absence, was plotted against the $\mathrm{CaCl}_{2}$ concentration. Symbols: EGCG, solid circle; GCG, hollow circle; ECG, solid triangle; and CG, hollow triangle. The line is the best fit for eq. (2), with $K_{\mathrm{d}}$ values of 3.8 and $2.8 \mathrm{~mm}$ for EGCG and GCG respectively.

A

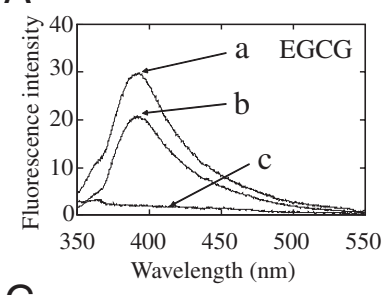

C

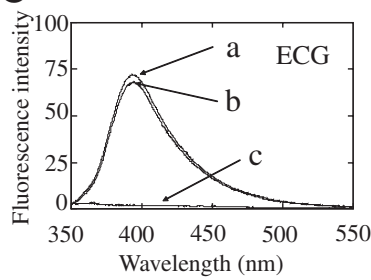

B

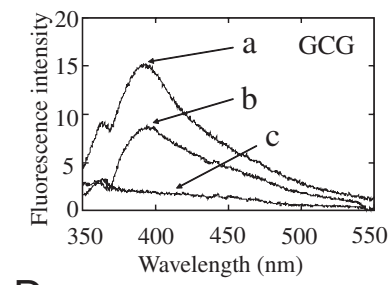

D

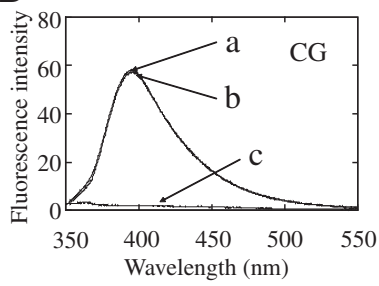

Fig. 5. Effects of MMP-7 on the Fluorescence of Green Tea Catechins.

Fluorescence spectra were measured with excitation at $325 \mathrm{~nm}$ and emission at 350-550 for $8 \mu \mathrm{M}$ EGCG (A), GCG (B), ECG (C), and $\mathrm{CG}(\mathrm{D})$ in $50 \mathrm{~mm}$ HEPES-NaOH containing $6 \mathrm{mM} \mathrm{CaCl}_{2}, 0.8 \%$ ethanol, and $0.8 \times 10^{-3} \%$ BHT in the presence (a) or absence (b) of $6 \mu \mathrm{M}$ MMP-7 at $\mathrm{pH} 8.5$ at $25^{\circ} \mathrm{C}$. The fluorescence spectra of the solution without catechins, $6 \mu \mathrm{M}$ MMP-7 in $50 \mathrm{~mm}$ HEPES-NaOH containing $6 \mathrm{mM} \mathrm{CaCl}_{2}, 0.8 \%$ ethanol, and $0.8 \times 10^{-3} \%$ BHT, are also shown ("c" in A-D).
A

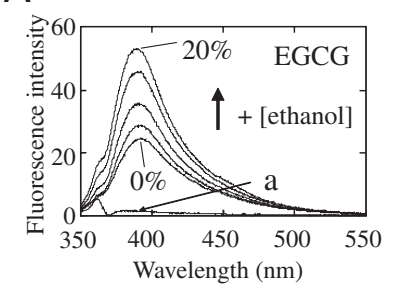

C

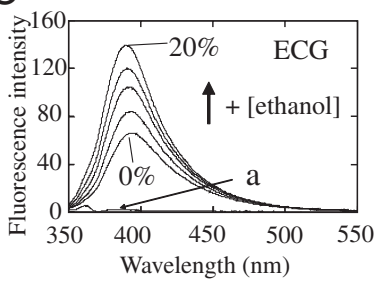

$\mathrm{E}$

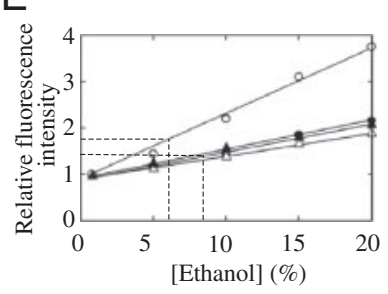

B

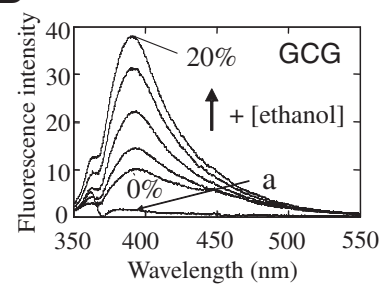

D

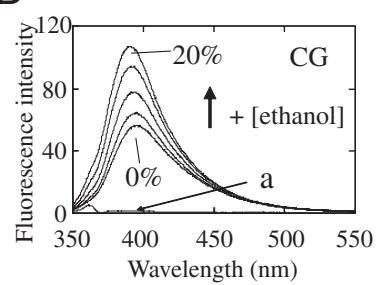

$\mathrm{F}$

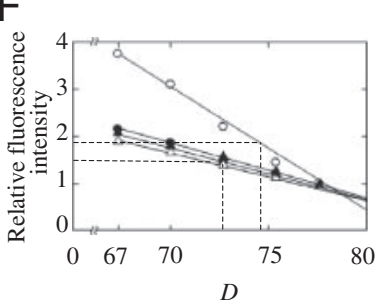

Fig. 6. Effects of Ethanol on the Fluorescence of Green Tea Catechins.

A-D, Fluorescence spectra. Fluorescence spectra of EGCG (A), GCG (B), ECG (C), and CG (D) were measured with excitation at $325 \mathrm{~nm}$ and emission at $350-550 \mathrm{~nm}$ for $8 \mu \mathrm{M}$ catechins in $50 \mathrm{~mm}$ HEPES- $\mathrm{NaOH}$ containing $6 \mathrm{mM}$ of $\mathrm{CaCl}_{2}$, various concentrations $(0$, $5,10,15$, and $20 \%$ ) of ethanol, and $0.8 \times 10^{-3} \%$ BHT at $\mathrm{pH} 8.5$ at $25^{\circ} \mathrm{C}$. The fluorescence spectra of the solution without catechins, $20 \%$ ethanol, $6 \mathrm{mM} \mathrm{CaCl}_{2}$, and $0.8 \times 10^{-3} \%$ BHT, are also shown ("a" in A-D). E and F, Relative fluorescence intensities. Relative fluorescence intensity was defined as the relative value of the area of the emission spectrum in a range of $385-400 \mathrm{~nm}$ in the presence of ethanol to the value in its absence. Symbols: EGCG, solid circle; GCG, hollow circle; ECG, solid triangle; and CG, hollow triangle. The dielectric constant $(D)$ is calculated according to eq. (1). The broken lines mean that the relative fluorescence intensities of 1.4 of EGCG and 1.8 of GCG correspond to ethanol concentrations of 8.8 and $6.3 \%$ respectively (E) and to $D$ values of 72.7 and 74.7 respectively $(\mathrm{F})$.

concentration of ethanol enhanced the fluorescence intensity of the four catechins (Fig. 6A-D). GCG exhibited the highest increase (Fig. 6E). The relative fluorescence intensities observed in the presence of $6 \mu \mathrm{M}$ MMP-7 (1.4 for EGCG and 1.8 for GCG) correspond to ethanol concentrations of 8.8 and $6.3 \%$ respectively (Fig. 6E), and to $D$ values of 72.7 and 74.7 respectively (Fig. 6F).

\section{Discussion}

The role of dissociation of the phenol hydroxyl groups of green tea catechins in the inhibition of MMP-7 activity

Catechins possess multiple dissociable hydroxyl groups. According to previously reported spectroscopic analyses, the hydroxyl group with the highest deprotonation potential of EGCG was the hydroxyl group at the $4^{\prime}$ position of the $\mathrm{D}$ ring, with a $\mathrm{p} K_{\mathrm{a}}$ of 7.8 , and that of EGC, which lacks the D ring, was the hydroxyl group at the 7 position of the $\mathrm{A}$ ring, with a $\mathrm{p} K_{\mathrm{a}}$ of $8.7 .^{38-40)}$ In this study, the inhibitory effects of EGCG, GCG, ECG, 
and $\mathrm{CG}$ increased with increasing $\mathrm{pH}$ from 7.0 to 8.5 (Fig. 2). The inhibitory effects of EGCG and GCG increased with increasing $\mathrm{CaCl}_{2}$ concentrations from 10 to $50 \mathrm{~mm}$ (Fig. 3). EGCG and GCG possess hydroxyl groups at the $5^{\prime}$ position of the $\mathrm{B}$ ring, while EGC and CG do not (Fig. 1). Hence we suggest that deprotonation of a hydroxyl group, presumably the one at the $4^{\prime}$ position of the B ring, is enhanced by the hydroxyl group at the $5^{\prime}$ position of the B ring in EGCG and GCG, but not in ECG and CG. We also suggest that this difference has to do with the difference in interaction with MMP-7 (Figs. 2, 3, and 5) and $\mathrm{Ca}^{2+}$ (Fig. 4) among the catechins with the galloyl group.

\section{Interaction of green tea catechins with $\mathrm{Ca}^{2+}$}

The fluorescence of EGCG and GCG decreased with increasing concentrations of $\mathrm{CaCl}_{2}$ from 0 to $45 \mathrm{mM}$ (Fig. 4). Assuming that one EGCG and one GCG molecule have two binding sites for $\mathrm{Ca}^{2+}$ with the same binding affinities, and that the fluorescence of the catechins decreases only when both sites are occupied with $\mathrm{Ca}^{2+}$, the relative fluorescence intensity $(F I)$ can be expressed as in eq. (2):

Relative $F I=1-\alpha \times \frac{\left[\mathrm{Ca}^{2+}\right]^{2}}{K_{\mathrm{d}}^{2}+K_{\mathrm{d}}\left[\mathrm{Ca}^{2+}\right]+\left[\mathrm{Ca}^{2+}\right]^{2}}$

where $\alpha$ is the maximum decrease in relative $F I(0.98$ for EGCG and 0.91 for GCG), and $K_{\mathrm{d}}$ is the dissociation constant of catechins with $\mathrm{Ca}^{2+}$. The results for the titration of relative $F I$ with $\mathrm{CaCl}_{2}$ fit eq. (2) well (Fig. 4E), suggesting that the stoichiometry of the catechins and $\mathrm{Ca}^{2+}$ is $1: 2$. From this fitting, the $K_{\mathrm{d}}$ values for EGCG and GCG were calculated to be $3.8 \pm$ 0.2 and $2.8 \pm 0.2 \mathrm{~mm}$ respectively.

In the presence of $10 \mathrm{mM} \mathrm{CaCl}_{2}$ plus $80 \mathrm{mM} \mathrm{NaCl}$ or $80 \mathrm{~mm} \mathrm{KCl}$, the inhibitory effects of catechins decreased as compared to those in the presence of $10 \mathrm{mM} \mathrm{CaCl}_{2}$ alone (Fig. 3). Unlike $\mathrm{CaCl}_{2}$, the fluorescence of the catechins was not affected by $90 \mathrm{mM} \mathrm{NaCl}$ or $90 \mathrm{mM} \mathrm{KCl}$ (data not shown). In that case, the mechanism of decrease in the inhibitory effects of catechins due to $\mathrm{NaCl}$ or $\mathrm{KCl}$ is not clear.

As for the binding of metal ions to catechins, Ghosh et al. reported that the absorbance of EGCG and ECG at $270 \mathrm{~nm}$ decreased with increasing $\mathrm{CuSO}_{4}$ concentrations at $\mathrm{pH} 5.0$, and that the stoichiometry of the catechins to $\mathrm{Cu}^{2+}$ was $1: 2{ }^{40)}$ They also found that the $\mathrm{Cu}^{2+}$ complex of EGCG inhibited RNase A activity at pH 6.0 with a $K_{\mathrm{i}}$ value of $23 \mu \mathrm{M}$, while the free EGCG did so with a $K_{\mathrm{i}}$ value of $81 \mu \mathrm{M},{ }^{41)}$ but the $\mathrm{Cu}^{2+}$ binding sites of EGCG and ECG were not identified. ${ }^{40)}$

\section{Interaction of green tea catechins with MMP-7}

The relative fluorescence intensities of EGCG and GCG in the presence of $6 \mu \mathrm{M}$ MMP-7 were 1.4 and 1.8 respectively (Fig. 5A and $\mathrm{B}$ ), which correspond to ethanol concentrations of 8.8 and $6.3 \%$ respectively (Fig. 6E). Assuming that all the EGCG and GCG molecules bound with MMP-7, the relative fluorescence intensities of EGCG (1.4) and GCG (1.8) correspond to dielectric constant $(D)$ values of 72.7 and 74.7 respectively (Fig. 6F). Although the percentage of catechins that bound with MMP-7 is unknown, these results suggest that the environments at the binding sites of
MMP-7 for EGCG and GCG are more hydrophobic than water.

According to a structural analysis of catechins complexed with chymotrypsin ${ }^{42)}$ and DNA gyrase, ${ }^{43)}$ the $\mathrm{A}$ and $\mathrm{C}$ rings penetrated deeply into the inside of the molecule, and the $\mathrm{D}$ ring was located at the surface. We speculate that in the catechin-MMP-7 complex, the B rings of EGCG and GCG are located inside the MMP-7 molecule and are surrounded by hydrophobic residues. In regard to this, Higashi et al. reported that the amino acid residues of MMP-7 involved in binding with cholesterol sulfate were all located at the molecular surface on the reverse side of the active site. ${ }^{8)}$ Identification of the amino acid residues of MMP-7 essential for binding with catechin is our next project.

In conclusion, EGCG and GCG inhibited MMP-7 activity more strongly than ECG and CG. We suggest that the presence or absence of the hydroxyl group at the $5^{\prime}$ position of the $\mathrm{B}$ ring has to do with the difference in interaction with MMP-7 among the catechins with the galloyl group.

\section{Acknowledgments}

This study was supported in part by Grants-in-Aid for Scientific Research (nos. 17380065 and 20380061, to K. I.) from the Japan Society for the Promotion of Science.

\section{References}

1) Woessner JFJr, FASEB J., 5, 2145-2154 (1991).

2) Nagase H and Woessner JFJr, J. Biol. Chem., 274, 21491-21494 (1999).

3) Woessner JFJr and Taplin CJ, J. Biol. Chem., 263, 16918-16925 (1988).

4) Browner MF, Smith WW, and Castelhano AL, Biochemistry, 34, 6602-6610 (1995).

5) Rawlings ND, Morton FR, Kok CY, Kong J, and Barrett AJ, Nucleic Acids Res., 36, D320-D325 (2008).

6) Yu WH and Woessner JFJr, J. Biol. Chem., 275, 4183-4191 (2000).

7) Yamamoto K, Higashi S, Kioi M, Tsunezumi J, Honke K, and Miyazaki K, J. Biol. Chem., 281, 9170-9180 (2006).

8) Higashi S, Oeda M, Yamamoto K, and Miyazaki K, J. Biol. Chem., 283, 35735-35744 (2008).

9) Lynch CC, Vargo-Gogola T, Martin MD, Fingleton B, Crawford HC, and Matrisian LM, Cancer Res., 67, 67606767 (2007).

10) Pajouh MS, Nagle RB, Brethnach R, Finch JS, Brawer MK, and Bowden GT, J. Cancer Res. Clin. Oncol., 117, 144-150 (1991).

11) Yoshimoto $M$, Itoh $F$, Yamamoto $H$, Hinoda $Y$, Imai $K$, and Yachi A, Int. J. Cancer, 54, 614-618 (1993).

12) Nakano A, Tani E, Miyazaki K, Yamamoto Y, and Furuyama J, J. Neurosurg., 83, 298-307 (1995).

13) Adachi $Y$, Itoh $F$, Yamamoto $H$, Matsuno $K$, Arimura $Y$, Kusano M, Endo T, Hinoda Y, Oohara M, Hosokawa M, and Imai K, Int. J. Oncol., 13, 1031-1035 (1998).

14) Muller D, Breathnach R, Engelmann A, Millon R, Bronner G, Flesch H, Dumont P, Eber M, and Abecassis J, Int. J. Cancer, 48, 550-556 (1991).

15) Happner KJ, Matrisian LM, Jensen RA, and Rodgers WH, Am. J. Pathol., 149, 273-282 (1996).

16) Miyazaki K, Hattori Y, Umenishi F, Yasumitsu H, and Umeda M, Cancer Res., 50, 7758-7764 (1990).

17) Imai K, Shikata H, and Okada Y, FEBS Lett., 369, 249-251 (1995).

18) Murphy G, Cockett MI, Ward RV, and Docherty AJ, Biochem. J., 277, 277-279 (1991). 
19) Inouye $\mathrm{K}$, Tanaka H, and Oneda H, J. Biochem., 128, 363-369 (2000).

20) Oneda H and Inouye K, J. Biochem., 128, 785-791 (2000).

21) Muta Y, Oneda H, and Inouye K, Biosci. Biotechnol. Biochem., 68, 2649-2652 (2004).

22) Oneda H and Inouye K, J. Biochem., 129, 429-435 (2001).

23) Muta $Y$, Oyama $S$, Umezawa $T$, Shimada $M$, and Inouye $K$, J. Agric. Food Chem., 52, 5888-5894 (2004).

24) Oneda H, Shiihara M, and Inouye K, J. Biochem., 133, 571-576 (2003).

25) Chung KT, Wei CI, and Johnson MG, Trends Food Sci. Technol., 9, 168-175 (1998).

26) Isemura $M$, Saeki $K$, Minami $T$, Hayakawa $S$, Kimura $T$, Shoji Y, and Sazuka M, Ann. NY Acad. Sci., 878, 629-631 (1999).

27) Demeule M, Brossard M, Pagé M, Gingras D, and Béliveau R, Biochim. Biophys. Acta, 1478, 51-60 (2000).

28) Garbisa S, Biggin S, Cavallarin N, Sartor L, Benelli R, and Albini A, Nat. Med., 5, 1216 (1999).

29) Maeda-Yamamoto M, Kawahara H, Tahara N, Tsuji K, Hara Y, and Isemura M, J. Agric. Food Biochem., 47, 2350-2354 (1999).

30) Garbisa S, Sartor L, Biggin S, Salvato B, Benelli R, and Albini A, Cancer, 91, 822-832 (2001).
31) Knight CG, Willenbrock F, and Murphy G, FEBS Lett., 296, 263-266 (1992).

32) Cha J, Pedersen MV, and Auld DS, Biochemistry, 35, 1583115838 (1996).

33) Muta Y, Yasui N, Matsumiya Y, Kubo M, and Inouye K, Biosci. Biotechnol. Biochem., 74, 2515-2517 (2010).

34) Oneda H and Inouye K, J. Biochem., 126, 905-911 (1999).

35) Muta Y and Inouye K, J. Biochem., 150, 183-188 (2011).

36) Muta Y, Oneda H, and Inouye K, Biochem. J., 386, 263-270 (2005).

37) Inouye K, Lee SB, Nambu K, and Tonomura B, J. Biochem., 122, 358-364 (1997).

38) Jovanovic SV, Hara Y, Steenken S, and Simic MG, J. Am. Chem. Soc., 177, 9881-9888 (1995).

39) Muzolf M, Szymusiak H, Gliszczyńska-Swiglo A, Rietjens IM, and Tyrakowska B, J. Agric. Food Chem., 56, 816-823 (2008).

40) Kumamoto M, Sonda T, Nagayama K, and Tabata M, Biosci. Biotechnol. Biochem., 65, 126-132 (2001).

41) Ghosh KS, Maiti TK, Mandal A, and Dasgupta S, FEBS Lett., 580, 4703-4708 (2006).

42) Gradisar H, Pristovsek P, Plaper A, and Jerala R, J. Med. Chem., 50, 264-271 (2007).

43) Smith DM, Daniel KG, Wang Z, Guida WC, Chan TH, and Dou QP, Proteins, 54, 58-70 (2004). 